\title{
Modern water-well drilling techniques in use in the United Kingdom
}

by

\author{
George Raymond Snewin Stow, T.D., B.Sc.(Eng)., A.M.I.C.E.
}

Mr G. M. Swales (Chief Engineer, East Surrey Water Company) opened the discussion by congratulating the Author on an excellent Paper. It was a long time since the Institution had had a Paper on the subject containing so much practical information. He proposed to confine his remarks to the reversed-circulation method of drilling, particularly in sand formations. Mr Swales had found that there were certain snags with this method, but they could be overcome.

122. One of the basic difficulties, as he saw the problem, was that often not enough was known about the site to design a borehole for this method of working. The method in sand was fast and things happened very quickly. It was possible to go down 30,40 , or $50 \mathrm{ft}$ in a day, and if one was not sure what one was going to do problems could arise.

123. If one wanted to put down a hole in the sand formation, then, unless one knew what the sand was like one did not know what size the gravel pack should be. Hence one did not know what size of slotted tube was required, and difficulties arose. The boring went on and the borehole reached the required depth. If at that stage the size of the slots in the slotted tube was decided, it might be found that there was a delivery time of two or three months, because the requirement could not be met from the contractor's stock. That being so, Mr Swales enquired whether the Author considered it necessary to have a trial hole or to obtain the necessary information about the sand in some other way beforehand, so that the gravel pack and the slotted screen tubes were on the site and everything was organized. The old percussion method was a more leisurely process and gave one more time to feel one's way.

124. As the Author had said, reversed circulation had the advantage of keeping the hole clean, but if it was necessary to go through clay for any considerable part of the depth, the drilling fluid would tend to become a mud and there would be mud circulation. It might then be necessary to make arrangements to throw away that part of the fluid after a while, have another lagoon, and start a clean hole just before going into the formation in which one was interested.

125. Mr Swales wished to comment on Fig. 1, the sand analyses. He was not proposing to argue about the Author's sizing of the gravel on this basis, but there were two points which he wished to make. The Author had five times the $50 \%$ size for his pack, which was in line with Terzaghi. Mr Swales's Company had done holes from three to six times, rather than keeping rigidly to five times, and most of them were quite satisfactory. He would, however, much prefer a pack of a far more uniform type than was shown in Fig. 1. The ideal pack was just a vertical line, all one size, but that was impracticable. This was a difficult type of material to obtain, but well worth the effort.

126. If it were possible to get a pack all one size, there would be much greater freedom in placing it, as segregation could not occur; all manner of difficulties would be overcome. He considered the placing of the pack to be one of the chief

*Proc. Instn civ. Engrs, vol. 23, September, 1962, pp. 1-14. 
aspects of a borehole of this type. If there were any slovenliness in placing the pack bridging would take place and there would be places with no pack. Therefore, when test pumping was started, sand would come in and there would be little that could be done about it. If an attempt were made to pump the sand out, more and more would come in, and experience showed that the pack did not seem to go down.

127. In that connexion he was concerned about the thickness of the pack, of 2-3 in. In view of the tolerance of the lining tubes mentioned elsewhere in the Paper he wondered whether with the size of the holes he had in mind, anything from 12 to 24 in., 2 or 3 in., was adequate. There might well be some part of the hole where a joint in the tube would meet a kink in the borehole which might give only $\frac{1}{2}$ in. In his opinion it was wiser to have a pack round about 4 in. rather than 2-3 in.

128. Finally, Mr Swales had one comment on television inspection. His Company had tried this in two boreholes, one of which gave a very impressive picture while the other was distinctly alarming. He wondered whether in introducing this type of equipment to well boring the Author's firm had not made a rod for their own backs. Future specifications might include a clause "After completion inspect hole by television'.

Mr F. Needham Green (Chief Engineer, Brighton Corporation Waterworks) associated himself with Mr Swales in congratulating the Author on his Paper. For too long, he thought, the ideas set out in it had been kept from people in the water industry. He was sure that the Paper would become a work of reference for those in his own position, who had to make only infrequent incursions into work of this kind.

130. He wished to deal with the last part of the Paper, which concerned the development of wells. In the near future in this country, and probably in many others, it would become increasingly necessary fully to develop any site where one started looking for water. It would be found that in the old days a watershed had been developed to the extent of the water requirements of that area. There were places to which it would be possible to return to get more water, but it would be very expensive. If in the first place a site was fully and properly developed, irrespective of the water that was wanted, more efficient results would be obtained. Too often in the past a well or borehole had been put down and as soon as a sufficient quantity had been found development was halted.

131. Mr Needham Green's only criticism of the Paper arose in that connexion. He would have liked the Author to go much more deeply into such questions as surging and acidification. The Author must have much more knowledge than he had given in the Paper. He might have felt that it would not be of interest, but $\mathrm{Mr}$ Green was sure that it would be. On the question of surging, for instance, more information on the extent to which this should be done would be of value. If there were more experimental work on that, or more correlation of results, it could be approached much more intelligently, but there was little evidence of any correlation of the facts.

132. The Author also mentioned shotfiring. In Mr Green's opinion that could be dangerous, because it could reduce the yield of a hole; but perhaps it was dangerous only because of the limited knowledge available as to its effects. The Author might have been lucky in never having reduced a yield. The method was not often used on a well or hole which was giving large quantities, and it was not possible to do much damage elsewhere, but the correlation of the results of shotfiring might be very useful.

133. In dealing with acidification the Author was on good ground as it had been used extensively, but again Mr Green had failed to find any correlation of results. How often should one acidify a hole? The Author gave some rough figures for the calculation of quantities, but one application was not necessarily sufficient. $\mathrm{Mr}$ Green had seen some results where a hole had been acidified five times and the increased yields plotted. The increase between the fourth and fifth applications had 
been almost negligible, but had been very considerable between the third and fourth, which suggested that many holes might benefit by more than one application. He had been concerned with one hole which had been completely dry, but one application of hydrochloric acid had made it into a useful well.

134. To digress a little on the need for full development of holes, the particular hole to which he had just referred was $500 \mathrm{ft}$ deep and $24 \mathrm{in}$. in diameter. It had been almost bone dry. It was not easy to do any very accurate mathematics on a hole of that type, but the work which they had done suggested, taking arbitrary figures for the porosity of the chalk, that the surface of the borehole was not cleanlycut exposed chalk. It was probable that in the process of boring the sides of the hole had been plastered, and that the acid had removed that plastering effect. Therefore, having drilled a hole, particularly by the percussion method, whatever the yield, it might be desirable to add acid to bring about complete development, using one or more applications.

135. In the Paper it was mentioned that it could be dangerous to use acid in a confined space, because of the $\mathrm{CO}_{2}$. That was obviously a danger. In the case of two holes of which he had experience, the whole of one plastic acid pipe had been blown out, due to pressure, and in the other, which had been capped after the introduction of acid, a column of water had been blown $60 \mathrm{ft}$ into the air 24 hours later when the cap was removed.

136. The problem in acidification, as the Author mentioned, was how to get rid of the $\mathrm{CO}_{2}$. With one hole where $\mathrm{Mr}$ Green had used acid there had been difficulty in disposing of the contaminated water left in the borehole after the acid treatment. He had taken up the problem with a horticulturist, who had not been worried about the $\mathrm{CO}_{2}$ but had taken the view that putting this water over the land would be equivalent to flooding it with sea-water. The chlorine content was the problem.

137. Similarly a problem arose with a hole $500 \mathrm{ft}$ deep where the water-level was about $100 \mathrm{ft}$ below the surface. It was not usual to put the pump more than about $150 \mathrm{ft}$ down, and that level of pumping would also be used to clear the hole of any water containing chloride. After that had been done, a conductivity probe of the borehole had shown water containing a very high dose of chloride below the pumping level. To the best of Mr Green's knowledge it was still there and he knew of no way of getting it out unless it was pumped from the bottom, $500 \mathrm{ft}$ down.

138. He hoped that in the not-too-distant future the Author would provide a great deal more information on both surging and acidification, which were essential parts of drilling a hole. So far as acidification was concerned, Mr Green included a standard clause in any borehole specification to include at least one treatment with acid.

139. The other point on which he wished to comment was the use of television. A previous speaker seemed to think that this might have repercussions. Mr Green had had quite useful experience with television which might be of interest to others. Curiously enough, he had tried to get television working in a borehole three or four years earlier to find the effect of acid treatment of the borehole. At that time there had been no instrument which could be put under water to the depths required. More recently he had wanted to know what happened in a borehole which was known to contain a fissure.

140. He then referred back to Fig. 5 of the Paper. This photograph was taken at a depth of $180 \mathrm{ft}$ below ground-level and $100 \mathrm{ft}$ below water-level. They were looking for a fissure, which was shown in the photograph, though the photograph was not as clear as the camera monitor. The fissure ran right across the borehole and was a bedding plane fissure. There had been evidence that this was on a possible line between the sea and a much larger station, and it had been thought that that larger station might draw sea-water back into itself when pumped heavily. The idea had been that if there was only one fissure and the borehole illustrated cut it, they could block the fissure and so stop sea-water coming to one of their major stations. 


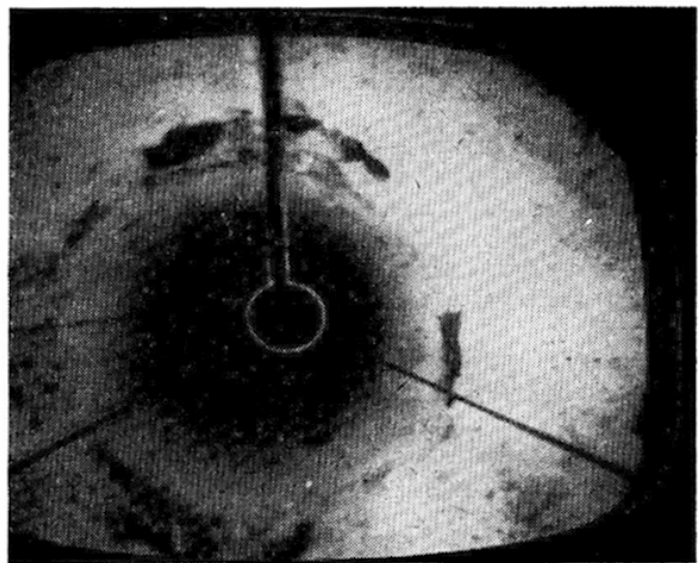

FIG. 7: FLINT BED INDICATED BY SHADOW WHICH DID NOT CHANGE WITH MOVEMENT OF CAMERA

Fig. 8: HeAdING ABOUT 4 FT WIDE AND 6 IN. HIGH CUTTING INTO BOREHOLE
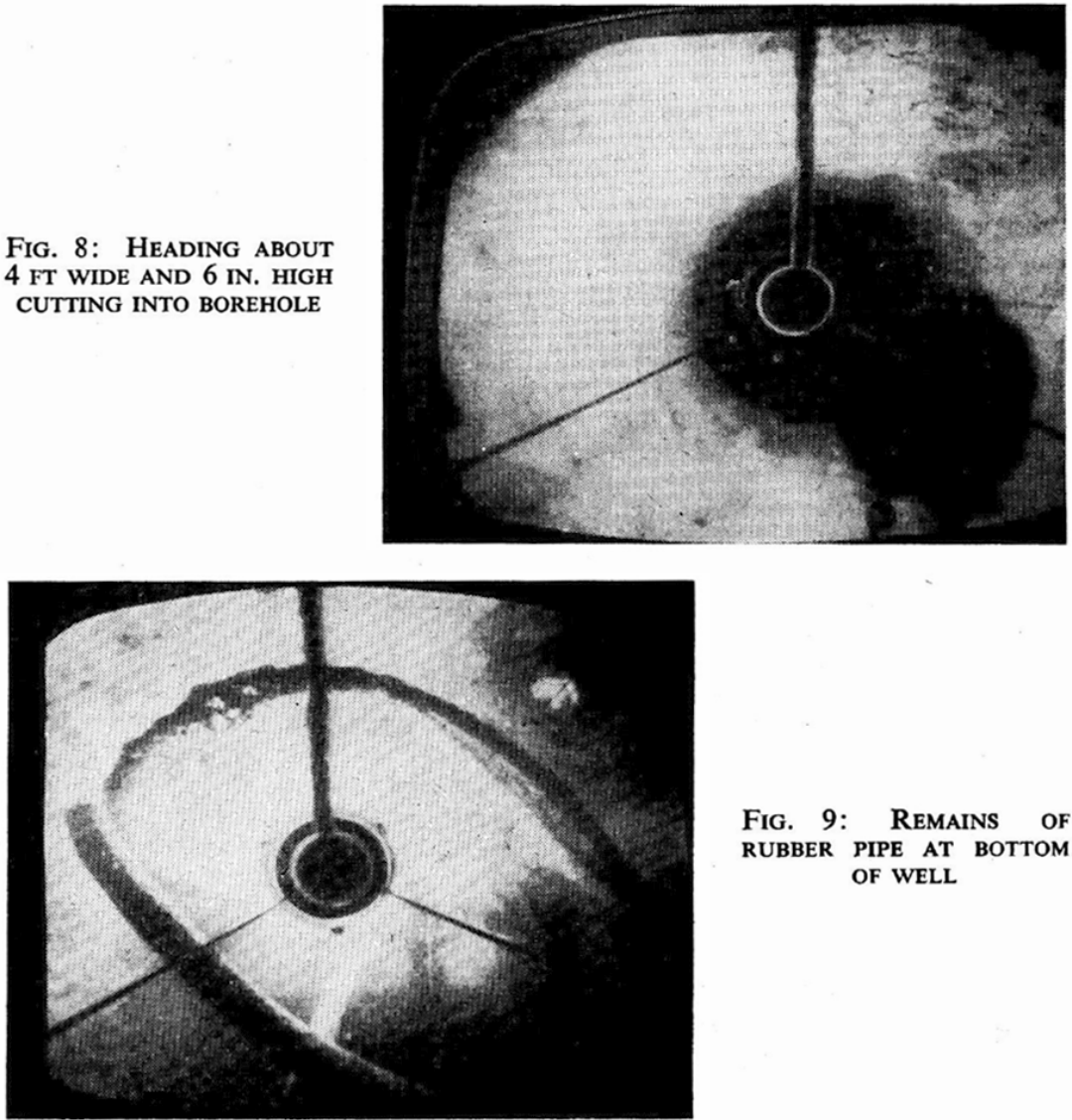

Fig. 9: ReMAINS OF RUBBER PIPE AT BOTTOM OF WELL 
They had known roughly the position of the fissure but they had not known the shape. They might have embarked on an expensive policy of blocking had not television shown that it was a bedding plane fissure and of a different type and shape from that at the other plant.

141. On the question of resolution: The fissure appeared on the photograph as a black shadow, and the picture on the screen had to be studied for a long time before the information which it gave could be fully appreciated. Movement of the camera would cause a shadow if there was a hole and it could be identified as such.

142. Fig. 7 showed a similar marking, but with any movement of the camera (the light source moved with the camera) there was no change in the shadow. It was a flint bed.

143. The top right-hand corner of Fig. 8 showed another position in the same well where a heading entered the borehole. The heading was about $2 \mathrm{ft} 6 \mathrm{in}$. high cutting into the 18 -in. borehole.

144. Fig. 9 showed the resolution at the bottom of the hole, $200 \mathrm{ft}$ below groundlevel. The remains of a rubber pipe used in chlorination, and other things which had been dropped down the well could be seen. The pictures reproduced did not do television justice from the point of view of what could be seen, but what had been said would indicate that a television camera had been found useful. Mr Green thought that in future its employment would become much more common and would be of undoubted help in solving some of the problems which arose.

Mr D. A. Brown (Sir Murdoch MacDonald \& Partners) congratulated the Author on compressing a very valuable record on the practical aspects of drilling into a small space. He had two questions. Dealing with reversed-circulation rotary drilling, the Author stated in $\$ 51$ that "provided the natural water-table is at least $6 \mathrm{ft}$ below ground level the excess water pressure in the well will support the walls'. It seemed to $\mathrm{Mr}$ Brown that when the groundwater level was at or near ground-level it might be necessary artificially to increase the static head of the circulation water-level above that of the natural water-table to support the sides. Had the Author come across that problem, and if so, how had he dealt with it?

146. In $\$ 92$ the use of aluminium for screens was mentioned. It would be interesting to know where that material had been used and with what success. If it had been successful, what was the alloy?

Mr A. Hope (General Manager, Wey Valley Water Company) said that he had intended to confine his remarks to the use of the television camera in boreholes but, in his introductory remarks, the Author had quoted recommended rates of flow through sand strata in connexion with gravel packed boreholes.

148. In Mr Hope's own undertaking, where practically all the boreholes were in the Lower Greensand, it was usual to bore through and line out the top 100 and $250 \mathrm{ft}$ comprising the Folkestone and Sandgate beds and to abstract water only from the Hythe beds, which were up to $250 \mathrm{ft}$ in depth, using 18-in. dia. slotted screen tubes backed by graded gravel packs within 27 -in. dia. bores. He wondered whether, in the Author's opinion, this was not an extravagant method and whether it would not be better to construct more boreholes of reduced diameter, e.g. 15-in. dia. with, say, 5-in. or 6-in. dia. screen tubes. Any pump could easily be accommodated in the 15-in. plain lining tubes as the draw-down was never in excess of $100 \mathrm{ft}$, and presumably, for the same rate of flow through the interface between the sand formation and the gravel pack, the total yield would vary directly with the diameter while the cost of the completed boreholes might vary as the square of the diameter. In other words, instead of constructing a group of four $27-\mathrm{in}$. boreholes one might achieve the same result by seven 15 -in. boreholes at a reduced cost.

149. The Author referred to the use of closed-circuit television for well and borehole inspections, and in Fig. 6 showed one of a series of photographs taken of the 


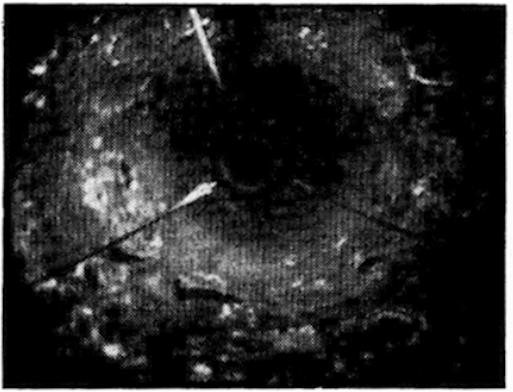

$\checkmark$ Fig. 10: SEVERE CORROSION PRODUCING PENETRATION OF TUBE
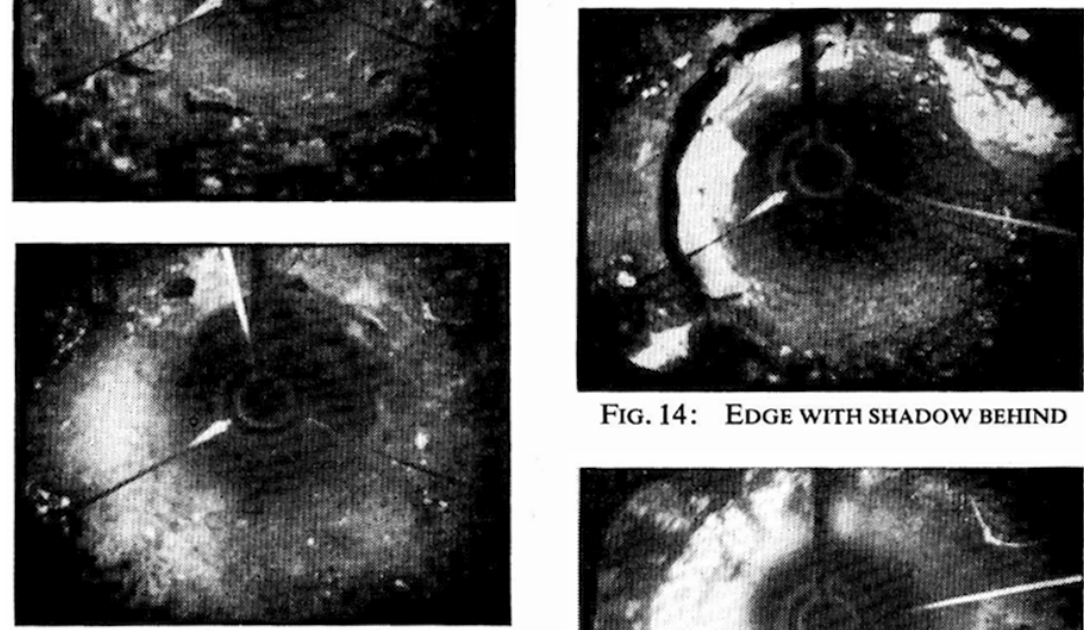

FIG. 14: EDGE WITH SHADOW BEHIND

FIG. 11: FURTHER HOLES AT 135 FT
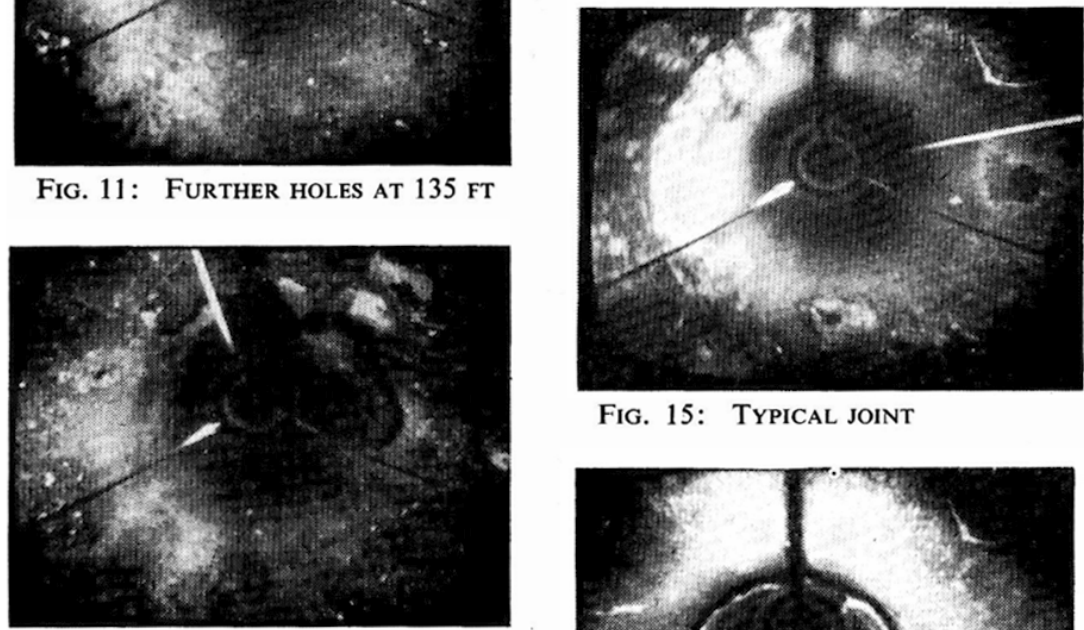

FIG. 15: TYPICAL JOINT

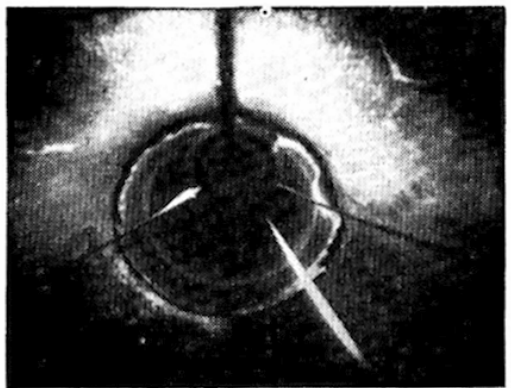

FIG. 16: TOP OF 12-IN. TUBE

$\triangle$ FIG. 13: 16-IN. TUBE EXPOSED AT $137 \mathrm{FT} 6 \mathrm{IN}$. BELOW FLOOR LEVEL 


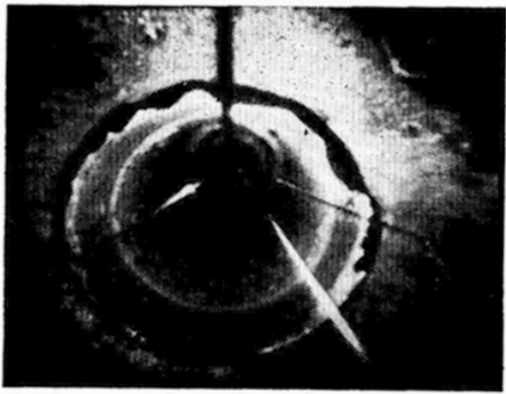

FIG. 17: Closer VIEW OF TOP OF 12-IN. TUBE WITH CURLING EDGE

FIG. 18: (Top right) ToP of 10-IN. TUBE

FIG. 19: (Right) MANY HOLES IN PERFORATED 10IN. TUBE BLOCKED AT 330 FT
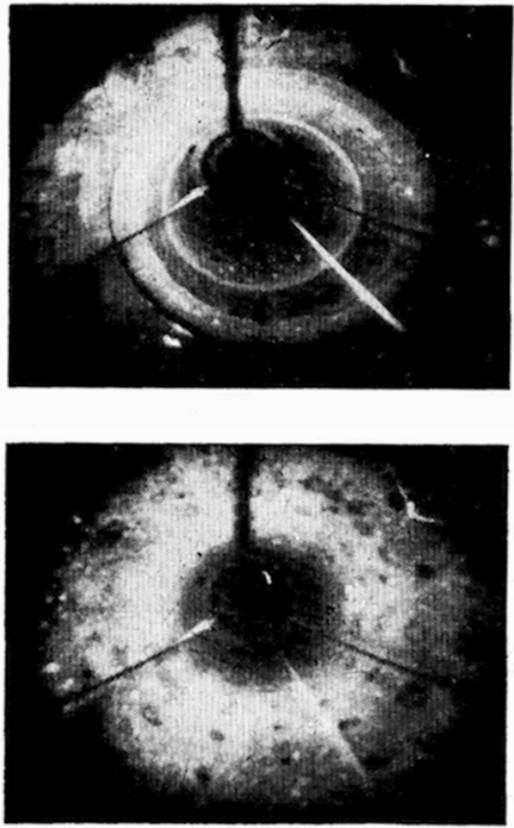

screen during such an inspection of one of the Wey Valley Water Company's smaller boreholes. This was one of a duplicate pair which had been acquired when the Company took over a local authority undertaking. Both boreholes had been drilled in the Lower Greensand to a depth of $400 \mathrm{ft}$. Starting off at the top at 20-in. dia., there were 10-in.-dia. perforated tubes for the bottom $75 \mathrm{ft}$ within the Hythe beds.

150. No. 1 borehole produced water with $1.5 \mathrm{mg} / 1$ of iron, while No. 2, only $10 \mathrm{yd}$ or even less away, had as much as $80 \mathrm{mg} / 1$ of iron. Inside the 20-in. tube, which penetrated only to $107 \mathrm{ft}$, there were 18 -in. tubes to $160 \mathrm{ft}, 16$-in. to $256 \mathrm{ft}$ and 14-in. to $325 \mathrm{ft}$, the two latter having cement seals at the base. As was usually found in old boreholes, both the 16-in. and the 14-in. tubes extended from the well head right through the ferruginous Folkestone and Sandgate beds into the Hythe beds, and it had been apparent, therefore, that either both linings had corroded through or that one or more seals had failed to function and that water from the Folkestone beds had been gaining access to the lower stratum.

151. The television camera had been put down to confirm the position and it had been found that the 14-in. tubes at least had broken up at about $135 \mathrm{ft}$ below the surface. Fig. 10, at $134 \mathrm{ft} 6$ in. below floor-level, showed severe corrosion producing penetration in the lower half of the picture, and there were further holes lower down, which in Fig. 11, at $135 \mathrm{ft}$, were shown to be only the precursors to a very large gap in the lining tube. Owing to the extremely wide angle of the lens the perspective was misleading and gave the impression that the distances down the bore from the camera were much greater than was in fact the case. Fig. 12, at $136 \mathrm{ft}$ below, showed still further holes. The main gap could be clearly seen with further holes lower down. The white line shown at roughly the one o'clock position was the reference plumb line which gave an idea of the orientation of the camera. The photograph shown in Fig. 13 was taken 18 in. lower down, at $137 \mathrm{ft} 6 \mathrm{in}$. It would be seen that the camera had rotated anticlockwise about $45^{\circ}$ and yet another split was revealed. It seemed clear that the 14-in. tube was missing altogether and that what was shown was the 
inside of the 16-in. tube. Fig. 14, 6 in. lower down at $138 \mathrm{ft}$, gave a very clear picture of the edge with the shadow behind. The camera had rotated still further anticlockwise.

152. That covered only a $3 \mathrm{ft} 6$ in. length of tube, the whole of the area affected. Fig. 15 was typical of the joints, all of which they had been able to see with the exception of one which should have been at the corroded section and one which could be seen not to have been screwed fully home. The lens could be focused by remote control and in this case it had been brought back to get as good a view of the joint as possible.

153. Fig. 16, taken at $300 \mathrm{ft}$, showed the top of the 12-in. tubes with the edge of the taper piece slightly curled over. The camera was now well over to one side and he thought that the lamp protector guide was actually resting on the side of the tube. That confirmed the previous verticality tests taken at the surface. Fig. 17 was the view 6 in. lower down. The lamp was just about to enter the tube and the focal plane was about 15 in. away from the top of the tube. Although the distance travelled was only 6 in. it appeared to be much greater.

154. Fig. 18 showed the top of the 10-in. perforated tube at $325 \mathrm{ft}$, which was shown to be in good condition. The inside view at $330 \mathrm{ft}$ (Fig. 19) showed many of the holes completely blocked. The camera had now rotated through $180^{\circ}$ since the start.

155. While this was being viewed, particles of debris could be seen descending the borehole and going out through some of the holes, thus confirming, had any doubt still remained, that there was a flow downwards in the borehole from the Folkestone beds into the Hythe beds.

156. The remedial works of inserting a new liner and of sealing were now partially complete, and already the iron in the water from the better hole, No. 1, was down to less than $1 \mathrm{mg} / \mathrm{l}$. In No. 2 borehole the bottom $140 \mathrm{ft}$ was found to be filled with sand, which when analyzed was found to come from the Folkestone beds as well as the Hythe beds. The standing water-level in No. 2 hole was $6 \mathrm{ft}$ below floor-level, while that in No. 1 was $11 \mathrm{ft}$. It was intended to put a pre-packed filter in the 10-in. section, so as to prevent sand ingress in the future.

157. Mr Hope thought that the under-water television camera was a most valuable new tool to the engineer and would enable him, as in the case described, virtually to travel all the way down a borehole to see exactly what was there. There had been some doubt about the depths recorded and it would be better to use a calibrated steel tape as the reference plumb-line, with distances printed on both sides. The most serious disadvantage was lack of colour, and what one saw were areas of less and greater reflectivity. Black and a gap were very similar, and white patches were not necessarily corrosion. No doubt within the next decade colour cameras would be produced for this purpose, providing all that could be desired for under-water inspection.

Mr M. W. Leonard (Director, Soil Mechanics, Ltd) referred to the last paragraph of the Paper, in which the Author had stated that many water-well drilling techniques were applicable to, and had been used for, bored piles and caissons.

159. He hoped that it would be of interest to the discussion to comment in broad terms on some of the plant and equipment used by boring and drilling firms in connexion with civil engineering construction, such as boring for in-situ piles or sinking wells for the purpose of lowering the groundwater table to enable construction to proceed. The common denominator of all such work was the capacity to employ the correct plant at the right time to meet the ground conditions.

160. He wished to refer to borings of a large diameter and in particular those that had to be lined. It had been found that, in order to facilitate the sinking of the casing tube there was advantage in oscillating it, and there were several ways in which the reciprocating motion could be applied to a sinking tube. 


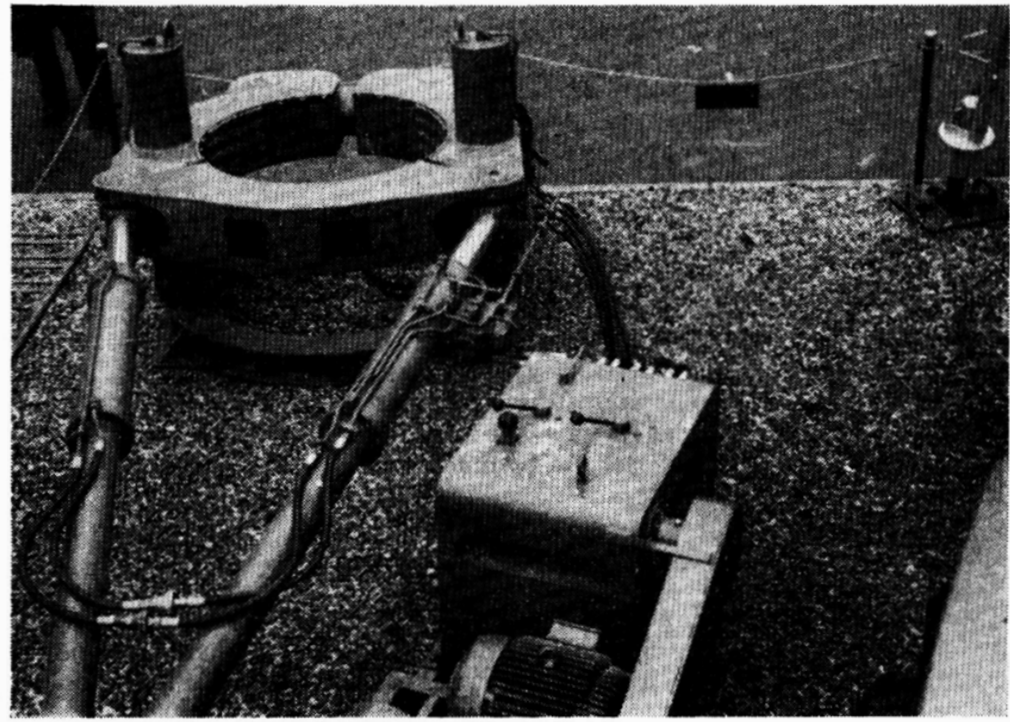

FIG. 20: LARGE DIAMETER BORING EQUIPMENT FOR OSCILLATING CASING TUBE

161. He recalled the Chairman, Mr H. J. B. Harding, telling him some years ago how, at Southampton, large borings had been sunk for the well system necessary to dewater the ground to permit excavation to be undertaken for the construction of the King George V graving dock. Mr Harding had mentioned the importance of being able to keep the tubes on the move, and he had used a large wooden clamp fixed round the casing; this was turned by hand using a long lever arm.

162. Today the practice was to provide an oscillating movement by means of hydraulic power through the medium of rams, and there were several ways in which this could be done; some of the principal features were illustrated in Fig. 20.

163. When borings were undertaken through soft ground and alluvial deposits, a grab (Fig. 21) was generally used to remove the spoil from within the boring. When hard formations were encountered, which could not be penetrated by the tines of the grab, a large chisel was employed. When boring was undertaken through clays which did not require the borehole to be lined to prevent collapse of the sides, a heavyduty power auger was very suitable. Most of these machines originated from America and generally consisted of a rotary table turning a telescopic Kelly Bar. They were capable of boring holes several feet in diameter and over $100 \mathrm{ft}$ in depth. The soil was removed by means of either a bucket or a helical auger attached to the foot of the Kelly.

164. In some cases, particularly when the formations were hard, the borings were sunk using percussion methods. Machines were now in operation in Britain employing the reverse circulation process, in which a percussion chisel was fixed to a hollow drill pipe through which drilling fluids, usually mud or water, were sucked up, bringing the debris in suspension to the surface for discharge there. Various chisels and bits were commonly employed, and each had individual merits or advantages, depending on the soils and rocks to be encountered.

165. Mr Leonard, in conclusion, said that he hoped the few slides he had shown would give some indication of the various fields in which the big boring machines 
could be employed to overcome ground conditions, and he felt it was paramount that these conditions should be properly understood before starting the main boring work.

Mr R. J. Slater (Deputy Engineer and Manager, Maidstone Waterworks Co.) observed that the Paper was of particular interest to water engineers, especially those practising in South-East England who had to abstract water from the Folkestone beds of the Lower Greensand. It was tempting to say that for them there was never a dull moment; either there was too much sand and not enough water or there was too much iron and not enough water, and often there was clogging up and wasting of the lining tubes.

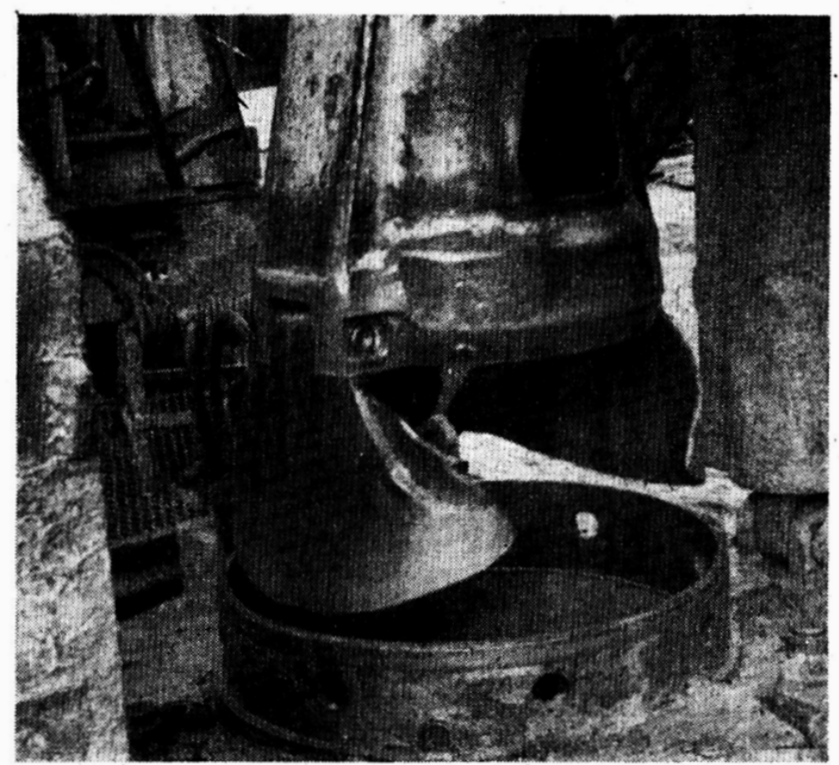

FIG. 21: GRAB USED FOR REMOVING SOIL FROM WITHIN STEEL CASING TUBE LINING AND BORING

167. It was ten years since the first graded filter pack had been used in this country, but he submitted that it was not until the reversed-circulation technique had been used in conjunction with either stainless steel or phosphor bronze screening-tubes and sand-retaining filter packs that any substantial and lasting improvement could have been looked for.

168. Insufficient time had elapsed for him to comment fully on the performance of two such holes which had been sunk recently for his Company, except to say that a reasonable yield had been maintained and that very little sand had been brought through. He was, however, interested to know whether the Author, in view of the experience which he had now had, was fully satisfied with this type of boring and in what directions he would try to make any improvements. In addition, would he agree that a very small amount of sand could be tolerated?

169. Other speakers had referred to the typical grading curves given in Fig. 1 of the Paper and had remarked that the $50 \%$ size of pack was described as being 
five times the $50 \%$ size of the formation. It had also been pointed out that this condition appeared to hold roughly between the $15 \%$ and $85 \%$ sizes and as such it would be just inside the Terzaghi limits. Had the Author found that any larger size of filter was of any advantage, bearing in mind that it would reduce the head loss? Apparently Mr Swales had found that a finer pack was more satisfactory and preferred a straight line grading. Mr Slater said he would have thought that a mixed pack would tend to encourage the formation of the filter.

170. Under the heading 'Development of wells' the Author had referred to the improvement in yields in chalk and limestone by the injection of hydrochloric acid. This was a form of treatment which had received much more attention over the past five or six years than previously and some of the results were truly staggering, but had they heard only of the successes and not of the failures? If so, would the Author recommend that this form of treatment be applied to all chalk holes, irrespective of the results of the initial pumping test? If so, could he give some indication of the cost, possibly as a percentage of the total cost of construction of the well? Better still, would he or anyone else be prepared to collate information on the use of acid and see what the result was?

Mr A. H. Stow (Engineer, Soil Mechanics, Ltd) congratulated his brother, the Author, on an excellent Paper and hoped it would provoke a very lively written discussion. It dealt with a subject which very much needed treatment. $\mathrm{Mr}$ Green had referred to the Paper as a work of reference, and that was what it might well become. That being so, $\mathrm{Mr} \mathrm{A}$. H. Stow made no apology for mentioning that there were a number of slips in the printed Paper to which he would call the Author's attention, so that he could consider them and if necessary incorporate corrections in his written reply.

172. Mr Brown mentioned aluminium screens and asked who was developing them. Intensive research into the question was being carried out. The manufacturer concerned was the Alcan Company of Banbury. Initial results showed that it was possible to make a satisfactory aluminium screen for given conditions, but not a universal one. The alloy was dependent on the particular conditions and the screen could be made to fit them. If anyone had a particular problem this firm would no doubt be able to help.

173. Mr Swales had referred to improvements in the reversed-circulation method. A startling improvement was obtained by the use of the compound air lift instead of the single air lift. The depth of about $500 \mathrm{ft}$ which the Author quoted was normal for a suction lift, but the weight of the material in the rising column so affected the density that it was very difficult with normal suction-pump reversed-circulation to go below $500 \mathrm{ft}$. An ordinary air-lift induced flow had been taken to $750 \mathrm{ft}$, but with great difficulty. The new system of compound air lift had been in use for about a year and 1000 -ft holes were now commonplace. It was possible to take a reversedcirculation hole in dangerous strata down to that depth.

174. With regard to acidification, the acid should be so placed and moved that it combined with and carried away in solution as much material as possible, to improve the entry of water into the borehole. It was of no value whatever to make large a fissure into a borehole and not develop back 2 or $3 \mathrm{ft}$ from that point. It was necessary to develop the whole area. The effectiveness of the acid action did not depend on pressure. In the past a very large proportion of the acid used had gone on the walls of the borehole rather than into the fissures and had even been trapped behind the casing. Excellent results had almost always been obtained, but often by excessive use of acid, and that was a matter of some concern because the dissolved material might travel with the underground water flow to the detriment of other users. Where the paper-making, brewing, and some other industries were concerned there might be heavy claims in consequence. Each scheme of acidification must be considered with 
expert advice on all the features involved, otherwise legal restrictions might be introduced which would deprive water authorities of a very useful aid.

Mr J. A. Dempsey (Engineer, Soil Mechanics, L.td), who confined his remarks to the question of gravel packs, said that until recently the work of his firm had been largely concerned with dewatering sites rather than with abstraction for supply, but the problems were exactly the same although possibly they might have been more concerned with the loss of ground; he referred to loss of ground under surrounding structures, to which the civil engineer had to pay attention.

176. The first consideration in the design of a borehole to abstract water was the uniformity coefficient of the sand formation, and the Author had referred to this. From their point of view the uniformity coefficient determined the permissible velocity at the interface between the formation and the pack or screen, and it varied from 3 to $15 \mathrm{ft} / \mathrm{h}$. Yields of from 10000 to $100000 \mathrm{gal} / \mathrm{h}$ had been obtained from 10 -in. screens in 24-in. boreholes, according to the uniformity coefficient of the formation and consequent appropriate treatment. The higher the coefficient and provided the sand particles were all one size, however small, the higher was the permitted interface velocity. If the grains were $\mathbf{0 . 2} \mathrm{mm}$ or larger they could be held satisfactorily, but if they were smaller there was difficulty in obtaining a screen with sufficient open area and fine enough slots.

177. There was a remedy however, and the basic fact about the gravel pack was that the sand material would not wash through the pack if the grain size of the pack was less than five times the grain size of the sand material. This could easily be demonstrated in the laboratory, or calculated assuming spherical particles. Fine sand with a high uniformity coefficient might be held and greater interface velocities permitted if the slot sizes in the screen were increased five-fold with a suitable thickness of gravel pack placed between the screen and the interface.

178. With some very fine sand and only comparatively coarse slots available, they had had to place a second pack outside the first, again one-fifth of the grain size, so that the slots were 20 to 25 times larger than would be necessary if placed in direct contact with the sand. Sands of moderate uniformity might be dealt with in a similar manner, but the uniformity could be improved by removal of the fine grains by swabbing, for example, or by considering that the fine grains are those to be retained and altering the slots. In such cases, however, natural sand with a small percentage of voids and a low interface velocity must be taken.

179. For sands of moderate or low uniformity the U.S. Waterways Experimental Station recommended that a pack should be chosen so that the $15 \%$ size of the pack was less than five times the $85 \%$ size of the sand formation. This was a compromise giving lower head losses but some passage of finer sands until the formation near the interface was impoverished. A graded pack was implied but the range of grading should be small. Unless this was so there was a danger of choking by incoming fines, as well as the constructional dangers of separation and segregation during placing. An excellent series of prepared gravel packs was available and the Author's ratios, slot sizes and typical curves indicated that he was using one of these. They would suggest a slightly coarser pack with a small amount of fines passing during test pumping, and much reduced head loss.

180. There was another method of developing progressive impoverishment by swabbing, etc., through special screens, but this was only practicable for small boreholes and had not been mentioned by the Author.

181. Plaster-coated steel screens were already much developed and some thousands of feet were actually in use. Considerable research into their development had been done. P.V.C., polyethylene, nylon, and P.T.F.E. coatings were available (in ascending order of cost, strength, and durability). 
Mr H. A. C. P. Hetherington (Technical Director, Le Grand ADSCO, Ltd) said the Author had given so much detail on various drilling methods that he could not usefully make any comments on them, but he wished to say a few words on the development of wells, a subject which some previous speakers had mentioned. Well development, or well stimulation as it was called in the U.S.A., definitely needed more consideration, as the Author had said. Not only could the yield of new wells be considerably increased by the use of acid or other methods but also the yields of old wells could be considerably improved.

183. Acid treatment seemed to arouse the most interest and was, Mr Hetherington thought, the most effective method of well stimulation. He had had to do with 22 treatments in the chalk in Southern England and he had had only one failure, which had been in an area where expectations had been low. In $9 \%$ of the cases treated the improvement in yield had been over $650 \%$, and in $62 \%$ of the cases there had been an increased yield of over $100 \%$, which he thought was very satisfactory.

184. These results compared fairly well with an analysis made in Missouri, U.S.A., where the failures had been $3 \%$. In $50 \%$ of the wells treated there had been a $100 \%$ improvement and in $10 \%$ an $820 \%$ improvement, a rather higher figure than he himself had obtained but of the same order. The figures which he had quoted represented the quantity of water pumped, but in almost all cases there had been a considerable rise in standing and pumping water-levels, so that the percentage improvement in the specific capacity had been very much higher, and he thought in one case had been $1400 \%$.

185. The first acid treatment of a borehole of which he had a record had been in 1945. The borehole had been sunk in 1930 and the initial yield had been $5000 \mathrm{gal} / \mathrm{h}$. In 1945 the yield had dropped, he believed, to about $900 \mathrm{gal} / \mathrm{h}$. After the acid treatment the yield rose to $10000 \mathrm{gal} / \mathrm{h}$ and held that level for two or three years. In 1948 it had been $8000 \mathrm{gal} / \mathrm{h}$ and it was still yielding this quantity, which was a fairly good record for acid treatment.

186. The Author had mentioned that nearby abstractors should be warned of acidizing operations and pumping stopped for a day or two. Mr Hetherington agreed that they should be warned, but added that the effect did not seem to be felt at quite such distances as had at one time been thought. Recently when he had acid-treated a borehole there had been no effect in another one $150 \mathrm{ft}$ away, and in west London, contrary to expectation, a borehole $100 \mathrm{yd}$ from the one treated had not been affected at all.

187. It was worth mentioning that the biggest increase in yield had always been obtained in boreholes with the largest diameter. He did not know why; perhaps the Author would comment.

188. Another treatment which had been successfully used was with Calgon. In some areas where it might be dangerous to use acid, Calgon could be used, and although the results were not spectacular, an increased yield of $40-50 \%$ could be obtained.

Mr J. G. Berry (Assistant Engineer, Scott and Wilson, Kirkpatrick and Partners) explained that he was not associated with any water undertaking, nor did he wish to undertake any propaganda; he approached the subject from the point of view of piled foundations and was interested in the verticality specification mentioned by the Author. A figure of 1 in 300 had been stated, and it appeared to him that this was very stringent. When putting down casings for bored piles or when sinking cylinders or driving bearing piles he did not think that such a standard was usual, and he wondered why there was this difference. Was it perhaps due to the fact that when drilling in rock it was easier to keep to the vertical than in soft ground? Was this figure of 1 in 300 actually achieved in practice? 
The following contributions were received in writing:

Mr L. E. Taylor (Well Engineer, Metropolitan Water Board) wrote that $\S 94$ of the Paper briefly referred to the development of wells by surging. The following example, which included the use of water from an adjacent borehole, might be of interest to members.

191. At the North Orpington Pumping Station of the Metropolitan Water Board, there were two 24-in. dia. boreholes: No. 1 borehole was constructed in 1943 and was $350 \mathrm{ft}$ deep; No. 2 was constructed in 1956 and was $400 \mathrm{ft}$ deep. The boreholes penetrated the Upper Chalk which was covered by $26-29 \mathrm{ft}$ of Drift and Thanet Sands. Both boreholes were lined to a depth of approximately $100 \mathrm{ft}$ below surface.

192. The test pumping of No. 1 borehole in 1943 showed that a yield of $1 \mathrm{~m} . \mathrm{g} . \mathrm{d}$. could be obtained from $80-90 \mathrm{ft}$ below ground-level-the standing water-level being $15-20 \mathrm{ft}$ below ground-level. It was thought that 1.5 to $2 \mathrm{~m} . \mathrm{g}$.d. could be obtained from the site; so it was decided that a second borehole should be sunk in the hope of obtaining a quantity similar to the first.

193. After the borehole had been sunk, an air lift apparatus with provision for back-blowing was installed, the apparatus being capable of a nominal output of $0.5 \mathrm{~m}$.g.d. from $100 \mathrm{ft}$ below surface. The initial run gave a yield of $0.17 \mathrm{~m}$.g.d. from $142 \mathrm{ft}$. Surging was carried out by alternately back-blowing and pumping for a total of 48 hours during a period of ten days. The water was seen to have a considerable sand content for the first two or three phases of pumping, but in course of time the sand content became less and less and there appeared to be only chalk in suspension. The final pumping indicated a yield of $0.47 \mathrm{~m} . \mathrm{g} . \mathrm{d}$. from $130 \mathrm{ft}$. (This figure was obtained while 1 m.g.d. was being pumped from No. 1 borehole.)

194. As the air-lift apparatus limited the draw-down, it was considered that further improvement could be obtained by lowering the pumping water-level and thereby increasing the size of the cone of depression and the volume of chalk affected. This was, in fact, attempted in October 1956 when a submersible pump was installed in the borehole with the suction at a depth of $276 \mathrm{ft}$ below surface. Development by pumping to increase the draw-down, stopping the pump to allow the water-level to recover and then pumping again at a high rate to try to achieve a cleansing flow through the fissures was carried out during the daytime from 17-29 October. These operations indicated a continued improvement in the yield and draw-down. Following this, a connexion was made from the pump in No. 1 borehole to deliver water into the top of No. 2 borehole which was sealed. The procedure adopted was to run the pump in No. 2 borehole to draw down the water-level and then simultaneously to stop the pump in No. 2 and start the pump in No. 1 borehole, discharging the water in No. 2. Water was 'backflushed' into No. 2 borehole for about $30 \mathrm{~min}$., in which time the water-level rose to the top of the borepipe. This cycle was repeated intermittently during normal working hours from 30 October to 3 November, and produced a further improvement in the yield of No. 2 borehole. In general, during 'backflushing' the water-level in No. 2 borepipe did not reach the top of the borepipe with the pump in No. 1 borehole delivering at a rate of 1 m.g.d. The total quantity of water 'backflushed' was about 200000 gal.

195. Test pumping was carried out from 6 November to 4 December, the water being discharged into a surface water sewer. The results showed that 1 m.g.d. could be obtained from a depth of approximately $64 \mathrm{ft}$ below surface compared with a yield of $0.47 \mathrm{~m} . \mathrm{g} . \mathrm{d}$. from $130 \mathrm{ft}$ after the first stage of development. The effect on the standing level in No. 1 borehole was less than $5 \mathrm{ft}$ when $1 \mathrm{~m} . \mathrm{g} . \mathrm{d}$. was being abstracted from No. 2 and the level was only depressed $7 \mathrm{ft}$ when $1.8 \mathrm{~m} . \mathrm{g}$.d. was being taken from No. 2 with a draw-down of over $100 \mathrm{ft}$.

196. The two boreholes were pumped together to establish the yield of the station and it was both interesting and encouraging to find that while 1 m.g.d. was being abstracted from each borehole, the pumping water-level in No. 1 borehole 
was $12 \mathrm{ft}$ higher than that recorded in 1943 when test-pumping of the borehole first took place.

Mr N. H. Hunt (Former Manager, Scott and Saxby, Calcutta) wrote that the Author had given members an informative paper on the latest techniques of drilling, which in his opinion was overdue. Despite the importance of water supply little had been brought before the Institution since the Paper given by Harding ${ }^{1}$ in January 1949 , when the subject of the Code had been discussed. This Paper and the subsequent discussion were very useful, and the present Paper taken with Mr Harding's gave a very good idea of how the work of boring etc. could be done. One other Paper, given by N. S. Boulton ${ }^{3}$ in December 1951, had also been very helpful.

198. The general position regarding drilling for water was perhaps not widely understood. A tube-well or boring was usually required in the larger sizes by a water-supply authority. A works requiring large quantities of water for its own use which it could not obtain from a supply authority, would usually sink a well.

199. It would be interesting in this connexion if $\mathrm{Mr}$ Stow would tell members what sanction had to be obtained before a well could be sunk in Britain, and whether details of the work and the type of strata met with had to be communicated to, say, the Geological Survey.

200. If the site of the works had been decided, the question of where the well should be sunk had to be considered, and this was usually a matter of experience. Perhaps, if no knowledge was available, a water diviner might be called in.

201. The works executives would know the quantity of water needed and this would decide the size of the well. The question of the contract for carrying out the work of sinking the well was usually a subject for discussion. If the contractor had knowledge of the strata and the possibilities of the quantity of water required being obtainable the problem might be straightforward, but otherwise no guaranteed quantity of water at any given depth for a given diameter of boring could be given. Perhaps Mr Stow could give some information on this subject which would be of use to members. The type of well to be sunk and the way it was finished off at the surface depended on the level of the water table and the type of pump to be used.

202. The pumps which could be used were:

(a) Ordinary centrifugal pumps if the water-level was near the surface, so that with the draw-down in pumping the suction head did not exceed $15 \mathrm{ft}$. If, as was sometimes the case, the well-house floor could be sunk $10 \mathrm{ft}$ or so, then a $25-30-\mathrm{ft}$ water level would be possible. With this method of pumping the top of the well could be finished of sufficient size to take the suction pipe and foot valve.

(b) Turbine pumps with a vertical shaft drive from the surface and submersible pumps and motors meant the top of the well had to be of sufficient diameter to take the pump and motor. As a set-off against this, in some cases a pump house was not needed.

(c) Under other conditions pumping could only be done by the use of compressed air.

(d) Formerly pumps installed in a well and worked by rods from the surface had been used, but it was questionable whether this method would be adopted in new work today.

203. Mr Hunt's experience had been chiefly in India, in the Ganges Delta, which Mr Stow evidently regarded as 'pie' for a well-sinker. The wells with which he had been concerned varied from 3 in. to $15 \mathrm{in}$. in diameter and the water-jetting method had generally been used, but over the whole of India, including the hilly regions of Assam where water was needed for the tea gardens, all types of drilling rigs had been used, much the same as those Mr Stow had described in his Paper.

204. In the Ganges Delta water in almost any quantity was obtainable at about 
$200 \mathrm{ft}$, but if very pure water was needed for drinking without further treatment it could be found usually in the same area at 500-700 ft.

205. Where a well was sunk near to another and on separate property the question of one well robbing the other had to be considered. Perhaps Mr Stow had met with this in his work.

206. When a well was first sunk it might give the desired quantity with a very small draw-down due to the fact that the surrounding sands and the screens were clean, but as pumping proceeded the draw-down increased until, depending on the quality of the water etc., the draw-down became so great that the pump became ineffective, or 'lost its suction' as it was usually termed.

207. The well could be acid-treated, a process which had to be carried out with some precautions, as $\mathrm{Mr}$ Stow had said. In Mr Hunt's experience the accumulation of mineral salts on the outer surfaces of the screens, especially if mixed with mica flakes, was very difficult to remove, and in cases where the well had been withdrawn for inspection the screens could not be cleaned effectively either chemically or mechanically without being damaged.

208. Acid treatment usually meant that the well was out of commission for six or seven days, which was very inconvenient unless an alternative well or storage capacity was available. A concluding point concerned the material of the pipes to be used for lining the well, which depended on the chemical composition of the strata. There were cases where holes $\frac{3}{4}$ in. in diameter had been found on examination of the pipes after a well had been in use for only twelve months, which of course meant resinking. On the other hand, in what was to all intents and purposes the same type of strata, the makers' stencil marks were still on the pipes after 25 years' service. In this connexion it would be of interest if Mr Stow could say what, if any, had been his experience with reinforced-concrete pipes, or with pipes of the resin materials now available.

209. Acid treatment often resulted in the output of the well being brought up to $85-90 \%$ of the quantity obtained when the well was new. The following figures for three wells near each other would confirm this.

$$
\text { Well No. } 1 \quad \text { No. } 2 \text { No. } 3
$$

Date of commencement of work . . . 9 Dec.

Depth of well

Result of back blowing with air . . . slight

Output before back blowing . . . . $8100 \mathrm{gal} / \mathrm{h}$

Output after back blowing .

Date of commencing acid treatment . . 12 Dec.

Output after acid treatment

Date of completion of work (18ft 6 in.)

$8525 \mathrm{gal} / \mathrm{h}$

$9000 \mathrm{gal} / \mathrm{h}$

$(9 \mathrm{ft})$

16 Dec.
19 Nov.

$314 \mathrm{ft} 8$ in.

slight and

some mica

$6750 \mathrm{gal} / \mathrm{h}$

(18ft 6 in.)

$7050 \mathrm{gal} / \mathrm{h}$

$(16 \mathrm{ft})$

25 Nov.

$9000 \mathrm{gal} / \mathrm{h}$

(11 ft 6 in.)

29 Nov.
30 Nov.

$322 \mathrm{ft} 3 \mathrm{in}$.

slight

$7500 \mathrm{gal} / \mathrm{h}$

( $20 \mathrm{ft} 9 \mathrm{in}$.)

$9000 \mathrm{gal} / \mathrm{h}$

$(16 \mathrm{ft})$

4 Dec.

$10800 \mathrm{gal} / \mathrm{h}$

$(9 \mathrm{ft})$

8 Dec.

The figure in parenthesis after the quantities was the draw-down.

210. As the wells were sunk in sand without additional sand being used near the screens, the criterion of the work had been taken as the quantity of water per foot of depression, as follows:

\section{Well}

No. 1

No. 2

No. 3

Before treatment

$437 \cdot 8$

365

362

Gallh per foot of depression

After treatment .

1000

773

1200 
211. From these figures it would be seen how important it was to take the drawdown into consideration when assessing results. One of the principal points noticed in years of work of this nature was that a record should be kept of the quantity per foot of depression from the time of commissioning the well, and that treatment in one form or another should be given before the interstices of the screens were filled to the extent that the acid etc. could not be forced through conveniently. The treatment had to be applied from inside while the bulk of the encrustation etc. was on the outside of the screens.

Mr A. H. Stow, supplementing the remarks he had made at the meeting, asked whether the Author would consider the following to see if corrections were necessary.

\section{Cable drilling}

213. $\$ 7: \mathrm{Mr}$ A. H. Stow thought that the drilling tools fell freely until, almost at the point of impact, the machine ceased to feed rope. Compression of the mast head buffer and stretch of the ropes occurred to allow the tools to continue and strike with a 'whip' or 'snap' action. The buffer, at maximum compression, assisted in the recovery of the tools for the next stroke. There was no release of the rope mandrel on impact. Jars would soon be hammered to breaking point under such use. When the tools paused at the point of maximum lift there was, momentarily, no load on the mandrel, and some left hand recovery took place. A good driller would, now and again, lower his tools to rest on the bottom, and as the jars slid to rest, fully open, the rope might be seen to spin.

214. $\$ 9$ : In soft rock penetration was no problem and a blunt bit drilled fast enough if only the debris could be mixed and held as slurry. In hard rocks the energy of blow should be concentrated on as small an area as possible and a sharp bit was needed. Had the Author been misled by the better support (flatter dressing angle) of the sharper bit and the greater area and modified reaming angle to protect against abrasion?

215. $\$ 14:$ Mr A. H. Stow thought that the use of static (not circulated) mud was to suspend the cuttings as a slurry and prevent cushioning of the drilling blow and, due to the piston effect of the chisel, that it would make an additional hazard in caving ground.

\section{Chilled shot drilling}

216. He thought the drilling action was as follows: Thechilled shot lay in the annular ring at the bottom of the hole; the core crown was lowered and rotated. The rotation of the crown, pressing upon the shot, caused them to roll and become distributed around the face of the core crown with excess shot up the inner and outer edges. The shot pressed between the core and the inner edge reduced the core diameter to give clearance and those on the outside cut clearance for the barrel. This clearance depended upon the size of shot used.

217. A useful demonstration might be given by rolling a single ball between a fiat plate and a smooth flat rock surface. Loading was increased until a deformation wave occurred (as in a ball race) and failure of the rock face into powder to give a groove. If a hemispherical point was pushed across the rock surface under the same loading a slight scratch only was caused and the effort required was great.

218. Abrasion using the shot would need an impractical torque. The appearance of core barrels when drawn, the rolling feel of drilling and the perfect roundness of all recovered shot confirmed this view.

219. The waterways were to assist in the distribution of the shot and to vent excess circulation water. Some small flow was necessary under the crown to wash away cuttings, but it was not to be too great otherwise shot would be displaced.

220. The results of experiments in breaking of cores had been published about a year earlier and the findings were opposite to those of the Author. A steady load 
applied for $10 \mathrm{~min}$. or more had been found to break tough unfractured rock cores that resisted repeated applications of sudden and much heavier loads. It had been suggested that time was needed for the loading to be transmitted through the rock. In the case of very large cores a very small explosive charge ( $\frac{1}{4} \mathrm{oz}$ gelignite) placed in a drilled hole at the centre and bottom of the core had been found to be completely effective even after failure of large charges placed in the annular space.

\section{Mud flush rotary drilling}

221. \$35: A data sheet of the Hughes Tool Company gave 600-200 ft of drill collar to achieve weight of $4000 \mathrm{lb}$ per inch of diameter for 6-12-in. holes. Was the loading right?

222. The toothed cutters were mounted on ball and roller bearings and would rotate even with light loading. The action of the teeth on the rock depended upon the type of bit used to suit the rock being drilled, and varied from the crushing action mentioned (for the hardest rocks) to a tearing action for soft rocks.

223. The returning mud velocity in the annulus should not be less than $60 \mathrm{ft} / \mathrm{min}$. or cuttings would circulate in the hole (instead of progress towards removal) and a dangerous situation was likely to arise.

224. The Author had mentioned the weight recorder but omitted the more vital penetrometer and the shale shaker-essential for removing cuttings from the mud as, due to gel strength, the fine cuttings would not settle out in any pit but were repumped to cause bearing failures and the worn bits he had mentioned earlier.

225. $\S 42: \mathrm{Mr}$ Stow had to assume that the Author's comments about mud flush drilling and muds had been based on the use of poor local clays or inexpert use of Bentonitic muds. Drilling muds were used successfully in oil sands with thousands of feet head of water differential pressure instead of the tens of feet common in waterwell work in Britain.

226. The mud wall should be impervious with less than $3 \mathrm{~mm}$ skin on the formation. The difficulties quoted when sand screens were used were typical of the improper use of drilling mud. It was a matter of concern to Mr A. H. Stow that a widely used and excellent technique was becoming discredited for water-well work in this country due to bad usage and lack of mud control.

\section{Reversed circulation rotary drilling}

227. The most recent development in this field was drilling with compound airlift with the air pipes built in to the sides of the drill pipe, and depths of $1000 \mathrm{ft}$ had become commonplace. This system had several advantages but was costly. Even so he agreed with the Author that the benefits of the reverse circulation systems were so great that they were likely to replace other systems for many conditions.

\section{Sand screens}

228. $\$ 86-92:$ The article by Harman T. Smith ${ }^{3}$ gave water-well contractors a useful method of constructing sand boreholes and they had drilled and packed many good boreholes in the Lower Greensand and some in other sand formations. The Author, however, had given no evidence of any development of Harman Smith's ideas or of any experiments to improve packs and $\mathrm{Mr}$ Stow thought it likely that many of the packs used could have been improved. The ideas set out by Mr J. Dempsey during Discussion might give a useful lead.

229. Mr A. H. Stow had been delighted to hear Mr Swales' suggestion of use of a pack of uniform grain size and believed that such a pack could be chosen to show an improved performance. The Author had said that such a pack could not be used as it would pass sand and Mr Stow would be grateful if he would set out his reasoning for this statement. 


\section{Shotfiring}

230. $\$ 96$ : He thought that the Author's figures for the size of the hole made by at directional charge were optimistic. In the case of chalk it was likely that a 'drummed' zone was caused around the blasted hole and drummed material was washed away by the test pumping flow, but if test pumping was delayed for a long period the drummed material would set and the hole remain comparatively small.

231. The size of hole, etc., was of some importance and he would be glad if the Author would let members know whether he had obtained any definite information on this. The television camera service by General Descaling Ltd, Worksop, seemed an ideal method of evaluation and he hoped that the Author had, or would, use this and publish the results.

\section{Acidification}

232. §§ 100-106: Mr Hetherington had said that in one case a borehole $150 \mathrm{ft}$ distant was not affected. Grood acidizing control should have placed effective acid beyond this distance unless there were very marked hydro-geological reasons to the contrary. The same comment applied to the Author's instance of boreholes $400 \mathrm{yd}$ distant.

The Author, in reply, thanked Mr Swales for his remarks and agreed that a trial borehole might be necessary to obtain sieve analyses of sandy aquifers, if there were no information from existing wells within a reasonable distance.

234. It was useful to call attention to the precautions mentioned in $\S 124$, which were normal practice.

235. The importance of exercising great care in placing gravel packs and on having a pack as uniform as possible was appreciated. There were, however, cases where it was desirable for the pack to cover a fairly wide range of grading. This would occur where the slots in the screen tubes would otherwise be too narrow to retain the pack (slot openings would be somewhat smaller than the size of a uniform pack but could be equal to the $25 \%$ size of a graded pack) or where there might be lenses of very fine sands included in the formation which would otherwise be drawn through the pack.

236. \$ 127: It was usual for each length of screen tube to have radial centralising lugs projecting 2 in. or more and for the well diameter in unconsolidated sands to be larger than the diameter of tool. This should ensure a minimum pack thickness of 2 in. It was agreed however that a uniform pack would be essential if the pack was thin.

\section{Mr Green}

237. The Paper was intended to describe various techniques and the principles involved and no attempt had been made to describe particular works, but the Author agreed that it would be most useful to correlate results of development procedure such as surge-pumping, shot-firing and acidification.

238. $\$ 133$ : On occasion it had been found necessary to apply two or three acid treatments, particularly where the thickness of water-bearing zone was small.

239. \$134: It had often been suggested that the walls of wells drilled in the chalk by percussion methods were plastered with drilling slurry. In the Author's opinion, unless the well had a low yield, this slurry was removed during test-pumping. The sides of many large-dia. wells had been inspected when first de-watered and found to be clean.

240. $\$ 136$ : No detrimental effect had been reported as a result of clearance pumping over grass lands and it was suggested that farmers would not be slow to complain if damage was caused.

241. $\$ 137$ : The Author thanked Mr. Green for raising this point and suggested that, for clearance-pumping after acidification, the suction of the pump should be 
placed close to the bottom of the well if this section of the well did not yield water. Otherwise there would be no means of clearing the chlorides from the bottom of the well.

\section{Mr Brown}

242. Where the natural water table was at, or near, ground level, it was necessary to build up the ground level around the well-site temporarily and to raise the level of the lagoon so that at least $6 \mathrm{ft}$ head could be built up in the well above the natural water table.

243. Aluminium-alloy screens had been used in cases where high $\mathrm{CO}_{2}$ was encountered. The alloy used was MG5 and the screens were believed to have been satisfactory. There might be trouble with electrolytic action through dissimilar metals if a pump were placed in the screen.

\section{Mr Hope}

244. The outside area of the filter pack to be provided for any required yield was difficult to estimate. Sandy aquifers might not be homogeneous and sometimes contained cemented or clayey beds. In most cases it was not possible to reproduce the exact conditions for laboratory tests. It was suggested that the entry velocity into the interstices of the pack, assuming 35\% pore space, should be taken at $0.003-0.015$ $\mathrm{ft} / \mathrm{s}$ for fine to medium sand formations having a uniformity coefficient closer than $5: 3$. An average figure from experience would be about $0.006 \mathrm{ft} / \mathrm{s}$ for free sands of the Lower Greensand at considerable depth. The depression of water level during pumping from a sand-screened well was usually less than $60 \mathrm{ft}$ but in some cases might exceed $100 \mathrm{ft}$.

245. $\S 148$ : The suggestion of spreading abstraction between a large number of small wells instead of fewer larger wells might show a small saving in the cost of the wells, but would almost certainly involve greater overall capital cost after taking into consideration the cost of pumps and piping. The smaller pumping units would be less efficient so that the running costs would be increased. It might be advantageous to spread the abstraction over a large number of small wells where a sufficiently large site was available, in order to reduce the drawdown for the purpose of restricting chemical precipitation.

\section{Mr Leonard}

246. $\$ \$ 160-162:$ The hydraulic racking or oscillating device was mentioned in $\S 18$ and illustrated in Fig. 2. This device was usually combined with vertical jacks for lifting or forcing down casing in addition to racking. This could be applied to almost any size of casing, the bottom edge of which could be saw-toothed to facilitate penetration of stable formations. The reciprocating motion imparted to the casing by the racking device with a torque of say 20-100 ton/ft broke down the skin friction so that the casing was forced down or, if necessary, extracted by the vertical jacks.

\section{Mr Slater}

247. It had been suggested that the maximum allowable sand inflow was 3 p.p.m. but it was believed that Mr Swales's experience was of less than 0.05 p.p.m., which would support his preference for the finer pack. Nevertheless, it was found that good results were obtained when using formations and packs of the type illustrated in Fig. 1, which related to the Lower Greensand.

248. \$ 169: Increasing the size of filter for a given output in order to reduce drawdown was a matter of economics, but in general, when dealing with the Folkestone Beds at considerable depth, it was not worthwhile increasing the filter area if a satisfactory sand-free yield could be obtained with a drawdown of say $60 \mathrm{ft}$, as the head loss through the filter was not very great.

249. \$170: Subject to difficulties of dealing with interference to existing wells 
nearby, it was nearly always advantageous to apply acid treatment to wells in the chalk and other limestones unless extraordinarily good results were obtained from initial pumping tests. It was rare to have a relative failure which might increase the yield by only $20 \%$. It was difficult to give the cost of acid treatment as a percentage of the total cost of the well as this depended so much upon the size and depth of casing and the rate of test-pumping, but a rough guide would be $20-40 \%$.

\section{Mr Stow}

250. \$174: The statement that the efficiency of acid injection did not depend upon pressure was contrary to experience of injecting thousands of tons of acid. The rate of acid injection and the pressure applied was of the utmost importance in ensuring that the acid was forced through small joints and fissures so that they might be enlarged for a considerable distance in the short time before neutralisation took place. In the absence of appreciable applied pressure there would be little tendency for the acid to travel away from the walls of the well.

251. \$232: If contact was made with a large fissure or solution channel in which there was a flow, the acid or the products of acidification would travel further from the well than if there were only a series of small joints and fissures.

252. \$213: The Author referred to the Ruston Bucyrus Armstrong Instructions for Cable Well Drills which quoted 'When tools are falling and the load is momentarily take off the line this mandrel permits the rope to twist itself back to its normal unloaded position. As the tools are picked up the mandrel grabs the socket, and the rope, in unwinding under the added load, turns the tools'. This supported the view that the rope mandrel was momentarily released on impact. He would however, agree that there would be less tendency for this to occur when drilling soft sticky formations. This momentary release of the mandrel would not be sufficient to hammer the jars. It should be emphasised here that the drilling wire rope should be 'lively' and have no pre-forming element in its manufacture to reduce its rotation in loading or unloading.

253. \$214: The American Bucyrus Erie Instruction Booklet on Cable Drill Bits for use in Granite, Quartzite, etc. quoted ' requires a drill bit with a wide angle of penetration which will form a thick, heavy cutting edge to withstand the impact of heavy tools on hard rock' and also quoted, 'when drilling in hard fissured limestone the penetrating angle should be greatly increased, making the bit very blunt'. The angle of penetration or the bevel on the cutting edge was shown as $120^{\circ}$, which must be considered relatively blunt. For soft formations smaller (sharper) angles of penetration were desirable with much more clearance behind the reaming edges.

254. \$215: The reason for using static mud was to support a relatively thin unstable formation until it could be cased in some way. However, a considerable mud column would be needed to prevent risk of caving and dilution of the mud as a result of bailing.

255. $\S \S 216-218$ : The procedure suggested in $\$ 216$ was highly dangerous and the tool would become 'shot-bound' in that any shot on the outside of the core barrel would tend to jam it in the hole. The minimum amount of shot should be used so that under the applied load the rolling action of the shot would crush the rock bebeneath. When drilling hard rock the shot was frequently reduced to dust and had to be replenished. In soft rock, however, there was a tendency for the shot to be pushed into the rock and not to rotate, and under these conditions the vertical loading had to be reduced. When drilling soft formation it would be possible to recover used shot in spherical condition. It was agreed that the abrasive action of the shot was small uniess one was dealing with very soft formation.

256. Only that shot which could be loaded by the bottom edge of the shotcrown would do useful work. If, by mischance, shot should occur and tend to rotate inside or outside the shot-crown it, could only have an abrasive or jamming action. 
257. \$220: The difficulties of breaking cores did not apply to normal welldrilling operations, but probably to drilling small depths into hard massive rocks, such that a core had to be broken off before reaching a bedding plane or joint, as might occur with drilling for piles or caissons. For water-well drilling, long core barrels of up to 25 -ft effective length were used. If it was not possible to break a core quickly, drilling was continued and a further attempt made, which was almost always successful and frequently at a bedding plane or joint. The core might break off at some distance from the bottom of the hole. It would be very expensive and laborious to have to break up cores by explosive charges or other means and to clean out the debris before continuing drilling. This condition sometimes arose when drilling shattered rocks which could not be lifted when coring at large diameter.

258. \&221: The Hughes Tool Company catalogue recommended loadings of 1000 to $5000 \mathrm{lb} / \mathrm{in}$. dia. for various rock-bits for use in soft to hard abrasive formations. It was appreciated that it was impossible to apply these loads from drillcollars on starting a well or at shallow depth, and pull-down mechanisms were used to apply loading to small-dia. tools. For large-dia. wells special large-dia. heavy drill-collars, not in accordance with A.P.I. standards, were improvised by contractors. Even so, the maximum efficient loading could rarely be applied for waterwell work.

259. $\$ 223$ : It was agreed that a mud velocity in the annulus of $60 \mathrm{ft} / \mathrm{min}$ was desirable. Much drilling of relatively shallow water-wells had been done with half this velocity, although the size of the cuttings removed would have had to be small and the mud would have had to have reasonable viscosity. Such situations usually arose in soft formations such as sands and clays where the cuttings would be small. 60 $\mathrm{ft} / \mathrm{min}$ would be equivalent to over $60000 \mathrm{gal} / \mathrm{h}$ for a 24 -in. well using $6 \frac{\text { s}}{8}$-in. drillpipe, and such mud velocities would rarely be justified or used for water-wells unless the diameter was small.

260. $\$ 225:$ Gas and oil pressures in an oil well were normally sufficient to remove any mud from the wall of the well and it was not usual to line such a well with a gravel pack or screens as for a water-well. The Author had knowledge of relative failures in water-well construction in three major oil-fields where it was presumed that all the technical 'know-how' on mud control was available. The gravel packs and screens of a number of wells drilled in this country by the mud-flush system had been overbored and extracted and found to be very largely choked with mud which had consolidated to the consistency of rubber. These wells were drilled by firms highly experienced in mud-flush drilling. In the Author's view, the use of mud-fiush systems for gravel-packed water-wells should be avoided where possible. If the system had to be used, a prepacked screen allowed more scope in demudding procedures.

261. \$229: The Author was in favour of a uniform pack which had considerable advantages in placing, but there were situations when a graded pack was preferable, as mentioned in $\$ 236$.

262. $\$ \S 230,231$ : It was not infrequent for flows of up to $2 \mathrm{~m}$.g.d. to pass through holes blasted by directional charges between wells but it would be interesting, in due course, to examine with a television camera the holes made by these charges.

\section{Mr Dempsey}

263. $\$ 176$ : The uniformity coefficient and the average grain size of the formation determined the permissible velocity at the interface between the formation and the pack. The Author's average figure of $0.006 \mathrm{ft} / \mathrm{s}$ for the Lower Greensand, given in reply to $\mathrm{Mr}$ Hope, applied to a $35 \%$ void space and corresponded to an average of $7 \frac{1}{2} \mathrm{ft} / \mathrm{h}$ on the interface area.

264. § 178: A double pack for dealing with a situation where only coarsely slotted screen was available was an interesting expedient.

265. $\$ 180$ : The method of development by progressive impoverishment by swabbing was mentioned in 887 . 
Mr Hetherington

266. \$187: It was usual to relate the quantity of acid to be injected to the diameter and unlined depth of the well and it was probable that this was responsible for larger wells giving greater increases in yield.

267. \$188: The Author's experience with Calgon had been to break down mud, sandy clays and clays in order to clear screens. This material would not be effective in enlarging fissures in limestone.

\section{Mr Berry}

268. American practice was that a well should not deviate more than half its diameter for each $\mathbf{1 0 0} \mathrm{ft}$ of depth. In the United Kingdom, however, a limit of 1 in 300 had been specified for many years. The reason for this specification was probably the need to accommodate shaft-driven turbine pumps of rigid construction which were required to be suspended vertically. The borehole diameter was selected in relation to the pump size so that it should hang vertically. These limits sometimes caused difficulties during construction but they were generally achieved and applied to depths of $400 \mathrm{ft}$ or to the depths at which pumps were to be installed.

\section{Mr Taylor}

269. The account of surge-pumping and back-flushing to develop two wells at North Orpington was most interesting. Possibly fissures in the upper part of the chalk were choked by fine sands carried down from the overlying Thanet Sands, and the surge-pumping was effective in clearing these fissures.

\section{Mr Hunt}

270. $\$ 199$ : Before a water well could be sunk in Britain, it had to be ascertained whether the area was scheduled under the Water Acts and, if so, it would be necessary to apply to the Ministry of Housing and Local Government for a licence to construct the well and abstract water at a specified rate. It was necessary to advertise the intention in a prescribed manner and the Ministry would consider the views of objectors before deciding whether a licence should be granted and on what terms. The procedure, however, was too lengthy to be detailed here and was likely to be changed by pending legislation.

271. The Water Acts required that the Geological Survey be notified before commepcing the works and that on completion they should be given full details of the work and the strata encountered.

272. $\$ 200$ : It was sometimes necessary to supplement geological advice by a geophysical survey, possibly using electrical resistivity methods to determine the position for a well. One liked to think that the problem was approached scientifically and in the Author's opinion the calling in of a water diviner would be equivalent, in rocketry, to placing an astrologer in series with a computer.

273. \$201: If the contractor had insufficient knowledge of the local strata and potentialities of the aquifers he could consult the Geological Survey, whose advice was freely available.

274. $\$ \$ 206-211$ : The treatment of chemical precipitation on well-screens in India was interesting but it would be useful to know the analyses of the water and the minerals deposited, the materials of which the screens were made and the nature of the gravel pack, if any. It might be an aggressive acid water and carbonates might have been deposited on the screens. The depth to rest water-level was not given, but it might have been better to have drilled deeper or sited the wells 'down dip' in such a position that the top of the screens would be about $100 \mathrm{ft}$ below pumping water level. This would reduce the tendency for $\mathrm{CO}_{2}$ to come out of solution and for carbonate deposition on the screens.

275. Rubber or plastic-coated steel screen tubes surrounded with a pre-formed gravel pack, the grains of which were given a film of resin to bond them together, 
should be effective. The pipe above the screens could be in similar plain steel, rubber or PVC coated. The Author had no experience of reinforced-concrete pipes for small wells to any depth.

276. The Author regretted two errors which had appeared in the Paper. The caption to Fig. 6 should have read 'Wey Valley Water Company,' and $\S 24$, line 5, should have read ' 2 in. on diameter'.

\section{REFERENCES}

1. H. J. B. HARdiNG. Site investigations including boring and other methods of sub-surface exploration. J. Instn civ. Engrs, vol. 32, 1949, pp. 111-157.

2. N. S. Boulton. The flow pattern near a gravity well in a uniform waterbearing medium. J. Instn civ. Engrs, vol. 36, 1951, pp. 534-550.

3. Harman T. Smith. Gravel packing water wells. U.S.A. Water Well J., Jan.-Feb. 1954.

4. H. E. Babbit, J. L. Doland and J. L. Cleasby. 'Water supply engineering,' 6th edition, McGraw-Hill, New York, 1962. 